\title{
Comercio internacional y pobreza mundial
}

\author{
Alieto Aldo Guadagni y Jorge Kaufmann
}

$\mathrm{T}$ eniendo en cuenta la magnitud de la pobreza mundial y el desafío que los Objetivos de Desarrollo del Milenio se han impuesto para reducirla, este artículo analiza una de las formas más claras y efectivas para disminuir la pobreza: la liberalización del comercio, en particular de productos agrícolas, por parte de los países industrializados. El 75\% de los pobres del mundo se halla en el sector rural de los países en desarrollo y los productos agrícolas que estos podrían vender enfrentan las barreras del proteccionismo — aranceles, medidas no arancelarias, subsidios - de los países industrializados. En el presente trabajo se examina en detalle este tema, tanto a nivel global como de productos específicos, y se presenta - a partir de diversos estudios - los beneficios que la liberalización del comercio de los países industrializados traería a los

Alieto Aldo Guadagni

Director Ejecutivo por Argentina,

Bolivia, Chile, Paraguay, Perú y Uruguay, ante el Directorio del Grupo Banco Mundial • aguadagni@worldbank.org

Jorge Kaufmann

Asesor del Director Ejecutivo por los países indicados ante

el Directorio del Grupo Banco Mundial

• jkaufmann@worldbank.org países en desarrollo, destacando la magnitud de la reducción de la pobreza que se lograría. 


\section{I}

\section{Introducción}

Para un lector no iniciado en materias económicas el título de este artículo podría generar más de una interrogante: ¿Qué relación puede tener el comercio internacional con las situaciones de pobreza y marginalidad que se ven en el mundo en desarrollo? ¿Qué relación pueden tener las imágenes de la carga y descarga de productos en puertos y aeropuertos o el cruce de fronteras por camiones y trenes de carga, con la miseria que se esparce en vastas zonas rurales de África, América Latina, Europa oriental y Asia? Se espera que estas páginas puedan dar luces sobre la estrecha vinculación que existe entre la pobreza en el mundo y las reglas que hoy imperan en el comercio internacional.
El presente artículo comienza por abordar temas de pobreza: los Objetivos de Desarrollo del Milenio, la evolución reciente de la pobreza en el mundo y su principal característica, que es su dimensión rural. Luego trata temas de comercio internacional, como los subsidios a la producción agrícola en los países industrializados y varios casos de productos agrícolas afectados severamente por el proteccionismo aplicado por estos países. Por último, presenta estimaciones de la reducción de la pobreza mundial que traería la erradicación de las principales medidas proteccionistas en la agricultura. Tales estimaciones no son de autoría propia, sino que corresponden a cuantificaciones de instituciones especializadas, principalmente del Banco Mundial.

\section{II}

\section{Los Objetivos de Desarrollo del Milenio}

En septiembre de 2001, las Naciones Unidas presentó un mapa de ruta con miras a implementar la Declaración del Milenio adoptada un año antes por sus 189 Estados Miembros, para que la globalización pudiese ser plenamente inclusiva y equitativa. ${ }^{1}$ Este plan comprometía el trabajo de los gobiernos y del sistema de las Naciones Unidas, incluidas las instituciones surgidas de la Conferencia de Bretton Woods - el Fondo Monetario Internacional (FMI) y el Banco Mundialy la Organización Mundial del Comercio (OMC), entre otras. Se basaba en los Objetivos de Desarrollo del Milenio, y apuntaba a lograr un desarrollo sustentable a través de la erradicación de la pobreza y el mejoramiento de un conjunto de indicadores sociales.

Los Objetivos de Desarrollo del Milenio son los siguientes:

1. Erradicar la pobreza extrema y el hambre.

2. Lograr la enseñanza primaria universal.

\footnotetext{
${ }^{1}$ Traducción nuestra.
}

3. Promover la igualdad entre los géneros.

4. Reducir la mortalidad infantil.

5. Mejorar la salud materna.

6. Combatir el síndrome de inmunodeficiencia adquirida (SIDA), la malaria y otras enfermedades.

7. Garantizar la sostenibilidad del medio ambiente.

8. Fomentar una asociación mundial para el desarrollo.

Cada uno de estos objetivos está asociado al cumplimiento de una meta específica y contiene la definición de indicadores de medición para monitorear y evaluar su logro. El objetivo de erradicación de la pobreza extrema implica reducir a la mitad el número de pobres - definidos estos como los que tienen un ingreso inferior a un dólar al día- entre 1990 y 2015.

Enfocaremos el análisis en este primer objetivo, ya que de alguna manera es un requisito para los restantes, y responderemos al siguiente par de preguntas: ¿Cuál ha sido la tendencia de la pobreza entre 1990 y 2000? ¿Cómo se proyecta su evolución hacia el año $2015 ?$ 


\section{III}

\section{Evolución de la pobreza en los países en desarrollo}

En el período 1990-2001 la trayectoria de la pobreza varía según la definición de pobres que se aplique. Si se considera que son pobres quienes viven con menos de un dólar al día — es decir, en pobreza extrema - se observa en ese período una reducción significativa de su número: de 1.219 millones a 1.101 millones. En cambio, si se considera pobres a quienes viven con menos de dos dólares al día, se comprueba que ellos aumentaron en ese lapso de 2.689 millones a 2.733 millones (Banco Mundial, 2004a).

Más importante aún, bajo ambas definiciones de pobreza la dispersión regional es muy significativa. La única región donde la pobreza disminuyó fue Asia; en las restantes el número de pobres se incrementó. En efecto, bajo la definición de ingresos inferiores a un dólar al día, la población pobre de Asia bajó de 934 a 712 mi- llones entre 1990 y 2001, mientras la de África en igual período subió de 233 a 321 millones y la de América Latina mostró un ligero ascenso de 49 a 50 millones. Si se consideran las personas con ingresos inferiores a dos dólares al día, en el período indicado los pobres disminuyeron en Asia de 2.075 a 1.927 millones y aumentaron en América Latina de 125 a 128 millones.

Las tasas de pobreza muestran mejores resultados. La proporción de pobres sobre la población total en los países en desarrollo cayó de 27,9\% en 1990 a 21,3\% en 2001, bajo la definición de ingresos inferiores a un dólar al día, y de $61,6 \%$ a 52,8\% si se aplica la definición de ingresos diarios menores de dos dólares al día.

El gráfico 1 indica que las tasas de pobreza no sólo caen en Asia, sino también en América Latina. Para el año 2001 se estimaba que 22,2\% de la población recibía

GRAFICO 1

Tres regiones: ${ }^{a}$ Tasas de pobreza extrema en países en desarrollo

(Porcentaje de personas que viven con menos de un dólar al día)

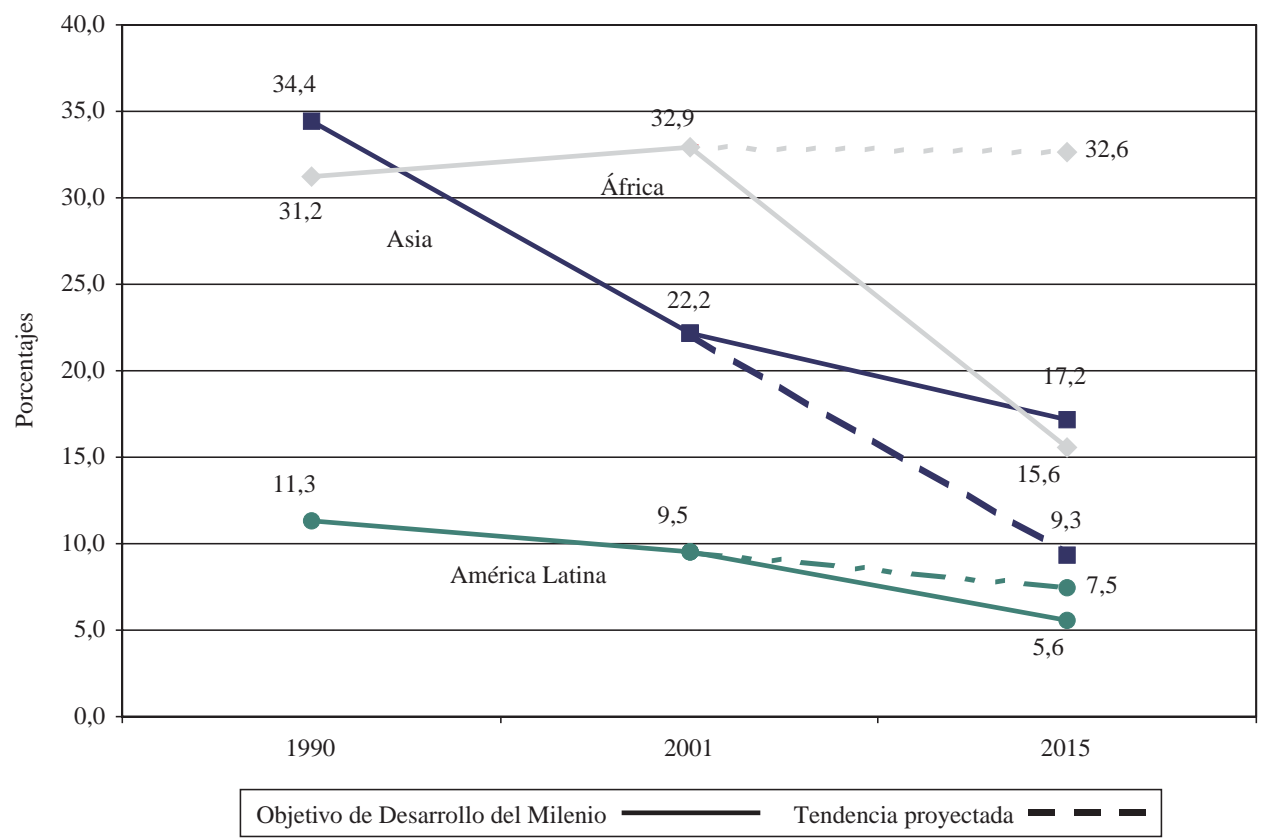

Fuente: Banco Mundial (2004 a y 2004 b).

a Para efectos de este análisis, África incluye a África al sur del Sahara, Medio Oriente y el norte de África. 
menos de un dólar al día en Asia, lo que representaba un significativo descenso respecto de 1990; sin embargo, la tasa era superior a la de 9,5\% de América Latina, donde la pobreza había retrocedido levemente desde $11,3 \%$. En el período considerado, Europa oriental aumentó su tasa de población en pobreza extrema de $0,5 \%$ a $3,7 \%$, y África de $31,2 \%$ a $32,9 \%$.

Es de interés analizar las previsiones sobre los niveles de pobreza que se alcanzarían en 2015. A nivel mundial, el número de pobres continuaría bajando, llegando a 809 millones en el caso de aquellos con ingresos inferiores a un dólar al día y a 2.320 millones en el caso de aquellos con ingresos diarios bajo dos dólares. Se estima que los pobres continuarán su rápido descenso en Asia y su aumento en África. En América Latina y Europa oriental descenderían desde los niveles vigentes en 2001, aunque esa reducción sería leve en la región latinoamericana.

Según esas proyecciones, la tasa de pobreza extrema en 2015 sería de $13,3 \%$ a nivel mundial, lo que significaría cumplir con la meta de reducir a la mitad el porcentaje de pobres de sus tasas prevalecientes en $1990(27,9 \%) .^{2}$ Por regiones, las tasas de extrema pobreza llegarían a 32,6\% en África, 9,3\% en Asia, $7,5 \%$ en América Latina y 1,4\% en Europa oriental. Sólo Asia lograría alcanzar el objetivo del milenio, con una tasa equivalente a casi la cuarta parte de la prevaleciente en 1990. América Latina - como se observano alcanzaría a reducir su pobreza extrema al 5,6\%, que es la meta ambicionada.

El cuadro 1 muestra lo que ocurriría con el número de pobres en todo el período considerado, es decir, de 1990 a 2015.

\begin{tabular}{|c|c|c|}
\hline & \multicolumn{2}{|c|}{$\begin{array}{l}\text { Países en desarrollo: Evolución de la } \\
\text { pobreza, 1990-2015 } \\
\text { (Variación en millones de personas) }\end{array}$} \\
\hline & $\begin{array}{l}\text { Personas que viven } \\
\text { con un dólar al día }\end{array}$ & $\begin{array}{l}\text { Personas que viven } \\
\text { con dos dólares al día }\end{array}$ \\
\hline Total & -410 & -369 \\
\hline Asia & -590 & -597 \\
\hline China & -304 & -611 \\
\hline Resto del mundo & 180 & 228 \\
\hline América Latina & -2 & -8 \\
\hline Europa oriental & 5 & -13 \\
\hline África & 177 & 249 \\
\hline
\end{tabular}

Fuente: Banco Mundial (2004a y 2004b).

Se observa que, en los 25 años que van desde 1990 a 2015, la pobreza extrema en Asia disminuiría en 590 millones de personas (y más de la mitad serían chinos), pero la miseria crecería en África y apenas disminuiría en América Latina.

En 1990, por cada pobre africano o latinoamericano había más de tres asiáticos pobres. En 2001 esta relación disminuyó a 1,8. Hacia 2015 habría apenas 0,74 asiáticos en pobreza extrema por cada pobre en el resto del mundo. Por otra parte, en 1990 de cada 10 personas en pobreza extrema en el mundo casi ocho eran asiáticas; hacia el año 2015 serían apenas cuatro. Es decir, la pobreza es cada vez más africana y latinoamericana y menos asiática.

\section{IV}

\section{Dimensión rural de la pobreza mundial}

Una característica esencial de la pobreza en el mundo es la siguiente: tres de cada cuatro pobres viven en áreas rurales (World Bank Institute, 2004). Por lo tanto, la proclamada lucha contra la miseria se gana o se pierde en el ámbito rural.

\footnotetext{
${ }^{2}$ En Banco Mundial (2004c) se presenta un escenario más optimista para 2015, que implica cumplir con el objetivo global más holgadamente, llegando a una tasa de extrema pobreza de $12,5 \%$. Dicho escenario contempla un crecimiento anual del producto interno bruto (PIB) de 4,7\% en 2004-2015.
}

Para el total de países donde se dispone de información por separado sobre el ingreso urbano y el rural, se encuentra que el $63 \%$ de la población y el $73 \%$ de los pobres viven en áreas rurales. Este tipo de proporcionalidad es común a todas las regiones. La incidencia de la pobreza rural es alta en todos los países en desarrollo, cualquiera sea su nivel de ingreso. La mayor parte de la población es pobre en los países de ingresos bajos; sin embargo, en los países menos desarrollados la tasa de pobreza de los hogares rurales alcanza a casi el $82 \%$. La participación de hogares rurales en el total de hogares pobres está declinando 
con la urbanización, pero aun así la participación rural en el número global de pobres no bajará del $50 \%$ antes de 2035 (Banco Mundial, 2003).

Para reducir la pobreza rural se necesita principalmente un aumento sostenido de la productividad de la agricultura en los países en desarrollo. Sin embargo, la responsabilidad de lograr ese incremento no radica exclusivamente en ellos. Por el contrario, para que esto sea posible es indispensable la apertura de los hoy cerrados mercados agrícolas de los países industrializados.

Estas últimas naciones — sin excepción algunatraban el libre acceso a ellas de la producción agrícola de los países en desarrollo, y además, en la mayoría de los casos distorsionan los mercados mundiales con subsidios a la producción y a la exportación agrícolas. Puesto que la pobreza rural es la más endémica y penosa forma de pobreza en el mundo, las trabas al libre comercio agrícola son esencialmente regresivas. Así, no habrá reducción apreciable de la pobreza mundial si no se facilita el crecimiento económico de los países en desarrollo, pero para muchos de ellos - parti- cularmente los más pobres- no habrá crecimiento sin avances tecnológicos en su agricultura.

Como los pobres producen principalmente bienes agrícolas, además de otros productos que hacen uso intensivo de mano de obra (textiles, por ejemplo), es evidente que el orden comercial mundial está sesgado contra ellos. Según estimaciones recientes, una liberalización global y equitativa del comercio podría disminuir en más de 300 millones de personas el número de pobres en el mundo, es decir, haría una contribución adicional de $60 \%$ a lo que se prevé alcanzar en los 25 años que finalizan en 2015 (Banco Mundial, 2001a).

En las reuniones bianuales del Fondo Monetario Internacional (FMI) y el Banco Mundial se aboga repetidamente por el fin del proteccionismo. Por ejemplo, en el comunicado final de la reunión ministerial del Comité para el Desarrollo de abril de 2003, se afirmó claramente que "es esencial que los países desarrollados se esmeren más en liberalizar sus mercados y en eliminar los subsidios que distorsionan el comercio, en los sectores de agricultura, textiles y vestuario, que revisten particular importancia para los países en desarrollo" (Comité para el Desarrollo, 2003).

\section{V \\ Los subsidios a la producción agrícola en los países industrializados}

El análisis del proteccionismo comercial en el mundo es un tema demasiado amplio como para abordarlo a cabalidad en pocas páginas. Por lo tanto, aquí sólo se procederá a presentar algunos antecedentes de la vasta evidencia disponible sobre las prácticas injustas que prevalecen en la actualidad.

Una de las más importantes inequidades que se observan en el sistema de comercio mundial y que obstaculizan el crecimiento de las exportaciones de los países en desarrollo, son los elevados subsidios agrícolas que aplican los países industrializados.

La Organización de Cooperación y Desarrollo Económicos (OCDE) estima que los productores agrícolas de sus países miembros recibieron en el período 2000-2002 un apoyo estatal que en promedio representó el $31 \%$ de su ingreso. Los mayores subsidios agrícolas se entregan en Suiza $(73 \%$ de los ingresos percibidos por el agricultor), Noruega (68\%), la República de Corea (66\%) e Islandia (63\%). Los producto- res agrícolas en Japón reciben un 59\% de su ingreso y en la Unión Europea un 35\%. Los agricultores de los Estados Unidos se hallan por debajo del promedio, con subsidios equivalentes al $21 \%$ de su ingreso (OCDE, 2003).

El cuadro 2 muestra la proporción de subsidios sobre los ingresos que reciben los productores agrícolas de los países industrializados por sus principales productos de exportación. El arroz, el azúcar, los lácteos y las carnes son los bienes más subsidiados.

Dichos subsidios no sólo tienen efectos dentro de las fronteras de los países industrializados; lo grave es que repercuten más allá de esas fronteras, deprimiendo los ingresos de los pobres que producen eficientemente estos bienes en los países en desarrollo.

Los subsidios agrícolas en los países de la OCDE superaron los 300.000 millones de dólares al año en 1999-2001, es decir, representaron más de seis veces 
CUADRO 2

Países industrializados: Subsidios por productos agrícolas de exportación, 2000-2002

(Como porcentaje del ingreso del productor)

\begin{tabular}{ll}
\hline Maíz & $27 \%$ \\
Carne de vacuno y ternera & $33 \%$ \\
Trigo & $37 \%$ \\
Otros cereales & $41 \%$ \\
Carne de ovino & $45 \%$ \\
Leche & $46 \%$ \\
Azúcar & $47 \%$ \\
Arroz & $81 \%$ \\
\hline
\end{tabular}

Fuente: OCDE (2003). la ayuda directa de los países industrializados a los países pobres. El monto señalado incluye subsidios tanto directos como indirectos, y son justamente estos últimos - las medidas restrictivas al comercio "en la frontera"- los que constituyen su mayor parte.

El volumen de apoyo agrícola por origen tuvo la siguiente composición: Unión Europea, 112.700 millones de dólares; Estados Unidos, 95.500 millones; Japón, 64.800 millones, y los demás países de la OCDE, 56.600 millones. Los principales productos beneficiados, por monto, son la carne (47.300 millones de dólares), la leche (42.100 millones), el arroz (26.400 millones), el trigo (17.400 millones) y el maíz (12.900 millones).

\section{VI}

\section{La fortaleza proteccionista}

En cuanto a los impuestos a las importaciones o aranceles aduaneros, los países industrializados han erigido una verdadera "fortaleza proteccionista", gravando en mayor medida a los bienes que producen los pobres (agrícolas y textiles), además de establecer numerosas barreras no arancelarias (cuotas, licencias, gravámenes antidumping y requisitos técnicos) que en muchos casos pesan más que los propios aranceles. En materia arancelaria, por ejemplo, los aranceles aduaneros a las importaciones agrícolas que aplica la Unión Europea alcanzan en promedio a $20 \%$, y a $9 \%$ en el caso de los Estados Unidos. ${ }^{3}$ En textiles y vestuario el arancel medio en los Estados Unidos es de 8,9\% y en la Unión Europea de 7,9\% (Oxfam International, 2002). Contrastan estas cifras con el arancel medio de tan sólo $1 \%$ que afecta a las importaciones recíprocas de estos mismos países desarrollados (The Economist, 2003).

El Instituto Internacional de Investigaciones sobre Políticas Alimentarias (IIIPA) estimó recientemente los efectos sobre las exportaciones de los países pobres que tiene esta fortaleza proteccionista. Según sus estimaciones, los países en desarrollo pierden alrededor de 40.000 millones de dólares al año por menores exportaciones debido al proteccionismo agrícola de los países industrializados. Esto significa que, de no me-

\footnotetext{
${ }^{3}$ Esta cifra esconde, sin embargo, una gran dispersión arancelaria, con aranceles máximos que llegan hasta el $350 \%$. Véase más información al respecto en CEPAL (2003) y Banco Mundial (2003).
}

diar las trabas proteccionistas, las exportaciones agrícolas de los países en desarrollo se triplicarían.

De esa pérdida, la cantidad mayor corresponde a América Latina, que actualmente exporta alrededor de 32.000 millones de dólares a los países industrializados y que podría exportar más de 46.000 millones; es decir, el perjuicio anual para esta región superaría los 14.000 millones de dólares.

Si se consideran los posibles ingresos de exportaciones no concretadas debido a las barreras al comercio, los países en desarrollo pierden ingresos netos de alrededor de 24.000 millones de dólares al año por el proteccionismo agrícola de los países industrializados; más de la mitad de esa pérdida deriva de la política agrícola común (PAC) de la Unión Europea. América Latina es la región más perjudicada, con una pérdida anual de ingresos estimada en 8.300 millones de dólares (IIIPA, 2003). Un ejemplo patético es el de los subsidios a la leche que se presenta en el cuadro 3.

\begin{tabular}{|c|c|c|c|}
\hline \multirow[t]{3}{*}{ u" } & \multicolumn{3}{|c|}{$\begin{array}{l}\text { "Tengo una vaca lechera, no es } \\
\text { una vaca cualquiera ..." }\end{array}$} \\
\hline & \multirow{2}{*}{$\begin{array}{l}\text { Cantidad de vacas } \\
\quad \text { (en millones) }\end{array}$} & \multicolumn{2}{|c|}{$\underline{\text { Subsidio por vaca (en dólares) }}$} \\
\hline & & Por año & Por día \\
\hline Unión Europea & 33,8 & 975 & 2,67 \\
\hline Japón & 1,6 & 4328 & 11,86 \\
\hline
\end{tabular}

Fuente: Cálculo propio a partir de datos de la OCDE. Efectuar esta comparación no es una idea original nuestra; por ejemplo, puede encontrarse un ejercicio similar en Stern (2002). 
Si los montos de los subsidios se dividen por el número de vacas que los reciben, se obtiene que el subsidio anual por vaca alcanza a casi 1.000 dólares en la Unión Europea y sobre 4.000 dólares en Japón. Llevando estas cifras al equivalente de subsidio diario por vaca, se obtiene que la Unión Europea le concede a cada vaca 2,67 dólares al día y Japón 11,86. Estos valores contrastan con la pobreza en que está sumida el África al sur del Sahara, donde el $48 \%$ de la población vive con menos de un dólar al día y el $77 \%$ con menos de dos dólares. La comparación entre los subsidios a las vacas en el mundo industrializado y la pobreza del Tercer Mundo impacta...

Una triste anécdota: el gobierno holandés —uno de los más generosos del mundo, en términos relativos, en cuanto a cooperación internacional - apoya a los productores lácteos de Tanzania hace más de 20 años. Pero, por otro lado, la Unión Europea exporta leche en polvo con subsidios que triplican la donación holandesa, empobreciendo así a ese país africano.

Los niveles de protección que enfrentan los exportadores de los países industrializados y aquellos de los países en desarrollo son extremadamente disímiles, lo que exacerba las injusticias del comercio
CUADRO 4

América Latina y países industrializados: Asimetría entre sus aranceles medios (Niveles de protección que enfrentan los exportadores en cada región)

Región importadora

Región exportadora América Latina Países industrializados

Bienes agrícolas

América Latina

$20,4 \%$

Bienes no agrícolas

Países industrializados $\quad 8,5 \%$

Fuente: Banco Mundial (2003)

internacional. Como muestra el cuadro 4, los bienes agrícolas provenientes de América Latina que acceden a los mercados de los países industrializados pagan, en promedio, un arancel de $20,4 \% .{ }^{4}$ En cambio, las exportaciones de bienes no agrícolas de los países industrializados entran a América Latina con un arancel medio de $8,5 \%$.

Así, el acceso de los principales productos de exportación de los dos grupos de países mencionados presenta una discrepancia arancelaria que llega a 2,4 veces.

\section{VII}

\section{Los pobres afrontan los aranceles más altos}

El cuadro 4 muestra que las exportaciones a países industrializados de los pobres de los países en desarrollo, en este caso particular los de América Latina, soportan aranceles más altos que los impuestos por los países en desarrollo a sus importaciones desde los países industrializados. La liberalización del comercio interno generalmente favorece a los pobres porque facilita el desplazamiento de recursos desde los sectores que hacen uso intensivo de capital a los que hacen uso intensivo de mano de obra.

Los países industrializados se aplican recíprocamente aranceles del 1\% sobre sus importaciones de manufacturas, pero gravan en $5 \%$ a las provenientes de Asia oriental, en 6\% a las del Medio Oriente y en $8 \%$ a las del sur de Asia. Mongolia, por ejemplo, paga en aranceles al gobierno de los Estados Unidos una cantidad cercana a la que le paga Noruega, aun cuando vende sólo 3\% de lo que Noruega exporta a los Estados Unidos. ¿Se puede argumentar que este sistema permite que los pobres aprovechen su potencial de desarrollo?

Algunas comparaciones efectuadas por Oxfam Internacional, una entidad británica, son elocuentes. Los aranceles de los Estados Unidos sobre las importaciones de los países en desarrollo llegan a ser más de 20 veces superiores a aquellos aplicados sobre las importaciones de otras naciones ricas. La tasa arancelaria media estadounidense sobre las importaciones provenientes de Bangladesh fue el año pasado de $14 \%$ y los pagos totalizaron 301 millones de dólares, aunque dicho país proveyó sólo el $0,1 \%$ del total importado por

\footnotetext{
${ }^{4}$ No debe desconocerse que también los países en desarrollo aplican significativos aranceles a los bienes agrícolas. Por ejemplo, las exportaciones agrícolas de América Latina pagan, por ejemplo, aranceles de $42,1 \%$ en el Asia oriental y de $24,7 \%$ en el África al sur del Sahara. Véase más información al respecto en Banco Mundial (2003).
} 
los Estados Unidos. Este valor fue sólo levemente más bajo que los gravámenes totales pagados sobre las importaciones desde Francia, a las cuales se aplicó un arancel medio de solo $1 \%$ y que representaron $2,4 \%$ del total de las importaciones de los Estados Unidos (Oxfam International, 2003).
Los aranceles de la Unión Europea discriminan severamente contra los países en desarrollo. Sus gravámenes sobre las importaciones desde India casi cuadruplicaron aquellos sobre las importaciones provenientes de los Estados Unidos, y fueron más de ocho veces mayores que en el caso de Sri Lanka y Uruguay. ${ }^{5}$

\section{VIII}

\section{Escalonamiento arancelario de los países industrializados}

Una de las características de la estructura arancelaria de los países industrializados es que desincentiva fuertemente la producción con mayor valor agregado, como ilustra el cuadro 5.

Esta situación prevaleciente en la Unión Europea, los Estados Unidos y Japón también se da en los restantes países industrializados. Por ejemplo, los aranceles de Canadá sobre los productos alimenticios procesados son 12 veces más altos que los aplicados sobre productos en su primera etapa de procesamiento.

El arancel de la Unión Europea es inferior a 4\% sobre las importaciones de hilados, pero de $14 \%$ sobre las prendas de vestir.

Los Estados Unidos y la Unión Europea aplican aranceles de $0 \%$ a las importaciones de cacao en grano, pero de hasta $30,6 \%$ sobre productos procesados como la pasta de cacao y el chocolate. Esto hace que los países en desarrollo produzcan más del $90 \%$ de todos los granos de cacao, pero menos de $5 \%$ de la producción mundial de chocolate.

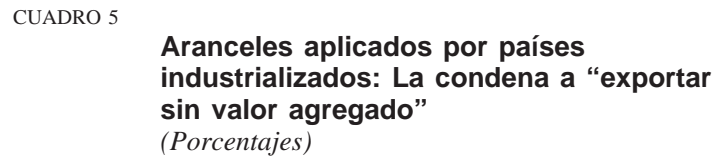

CUADRO 5

Aranceles aplicados por países industrializados: La condena a "exportar sin valor agregado" (Porcentajes)

\begin{tabular}{|c|c|c|c|c|}
\hline \multirow{2}{*}{\multicolumn{2}{|c|}{ Producto exportado }} & \multicolumn{3}{|c|}{ Arancel aplicado por } \\
\hline & & Unión Europea & EE.UU. & Japón \\
\hline \multirow[t]{2}{*}{ Café } & Materia prima & 7,3 & 0,1 & 6,0 \\
\hline & Producto elaborado & 12,1 & 10,0 & 18,8 \\
\hline \multirow[t]{2}{*}{ Cacao } & Materia prima & 0,0 & 0,0 & 0,0 \\
\hline & Producto elaborado & 30,6 & 15,5 & 22,0 \\
\hline \multirow[t]{2}{*}{ Azúcar } & Materia prima & 18,9 & 2,0 & 25,0 \\
\hline & Producto elaborado & 36,4 & 17,7 & \\
\hline \multirow[t]{2}{*}{ Fruta } & Materia prima & 9,2 & 4,6 & 8,7 \\
\hline & Producto elaborado & 22,5 & 10,7 & 16,7 \\
\hline
\end{tabular}

Fuente: Banco Mundial (2003).

a Específico.

\section{IX}

\section{Los más ricos reciben los mayores subsidios}

\section{Inequitativa distribución de los subsidios agrí- colas}

Los países industrializados se beneficiarán por la reducción del proteccionismo y de los subsidios a la agricultura, la mayor parte de los cuales va a grandes agricultores que ganan más que la familia promedio en la Unión Europea, Japón y los Estados Unidos. El pro- teccionismo y los subsidios cuestan 1.000 dólares al año a la familia promedio de estas regiones, por el mayor costo de los alimentos.

En muchos países industrializados, el ingreso medio de los agricultores es más alto que el ingreso medio

\footnotetext{
${ }^{5}$ Oxfam International (2003).
} 
nacional: $250 \%$ en los Países Bajos, $175 \%$ en Dinamarca, $160 \%$ en Francia y $110 \%$ en los Estados Unidos y Japón.

La OCDE calcula que sólo un cuarto de cada dólar de apoyo al productor llega al bolsillo de los agricultores; el resto va a los proveedores de insumos y dueños de otros factores de producción. El más importante resultado de estos programas de apoyo es que inflan los precios de la tierra.

Un trabajo reciente (Environmental Working Group, 2003) ha dado a conocer algunos antecedentes que ilustran esta inequitativa distribución de los subsidios agrícolas. En los Estados Unidos las grandes explotaciones son las principales responsables del aumento de los excedentes de producción agrícola que se exportan, con lo que acumulan una participación aún mayor de tales pagos. En 1995 los grandes productores recibieron 4.000 millones de dólares (el 55\% de todos los subsidios agrícolas federales) y en $2002 \mathrm{su}$ participación se elevó a 7.800 millones (65\%).

En los Estados Unidos el 25\% de los predios más grandes percibe $89 \%$ de los subsidios, mientras que los restantes 1,6 millones de predios del país reciben un bajo apoyo. En 2001 la lista de receptores de subsidios agrícolas incluyó a David Rockefeller y Ted Turner.

En la Unión Europea la distribución del apoyo no es diferente. El cuartil más alto de los productores agrícolas, en términos de tamaño de los predios, reciben cerca del $75 \%$ del apoyo total (OCDE, 2003) y el $4 \%$ de agricultores con los predios más grandes reci- be el $21 \%$ del apoyo. Los predios que les siguen en tamaño generan $17 \%$ del producto agrícola y reciben $19 \%$ de los subsidios. Los dos millones de predios restantes producen poco y reciben un apoyo mínimo.

En Japón y Canadá los predios que componen el $25 \%$ de mayor tamaño reciben $68 \%$ y $70 \%$ del apoyo total.

\section{Medidas antidumping}

Respecto a efectos de la aplicación de medidas antidumping —otro instrumento que provoca inequidades - en el recuadro 1 se presenta a título ilustrativo un caso vinculado a Vietnam, sobre la base de información del Banco Mundial (2003).

Ante el perjuicio potencial de las medidas antidumping, como el que se señala en el último párrafo del recuadro, hay países que en forma bilateral han eliminado la posibilidad de aplicación recíproca de tales medidas. Es lo que se hizo, por ejemplo, en el Tratado de Libre Comercio entre Chile y Canadá de 1996.

\section{Algunas medidas proteccionistas relativas a bienes agrícolas importantes}

A continuación se describen brevemente algunas medidas proteccionistas que afectan al comercio de bienes agrícolas que son clave en la producción mundial. ${ }^{6}$

${ }^{6}$ Muchos de los antecedentes presentados provienen de Banco Mundial (2003).

\section{RECUADRO 1 \\ UNA HISTORIA VIETNAMITA}

Después de embarcarse decididamente en reformas no marxistas, Vietnam exhibió una de las más brillantes historias de globalización de la década de 1990. Este país, tras haber sido importador de arroz, se transformó en el segundo más grande exportador arrocero del mundo y en un actor en el comercio global de café.

Se estima que al cabo de unos pocos años, medio millón de vietnamitas vivían del negocio del catfish (siluro, barbo o bagre), fomentado por empresarios privados. Vietnam llegó a capturar el 20\% del mercado de filete congelado de este pez en los Estados Unidos, haciendo bajar los precios, ante el pavor del Mississippi Farm Bureau.

Recientemente el Departamento de Comercio estadounidense impuso aranceles que van del $37 \%$ al $64 \%$ sobre el catfish vietnamita. La Comisión de Comercio Internacional de los Estados Unidos dio su veredicto final el 23 de julio de 2000: estableció que la industria del catfish estadounidense fue dañada por la competencia desleal que significó el dumping de Vietnam, con lo cual dichos aranceles se hicieron permanentes.

Algo parecido pasó hace dos años con la miel argentina.

Cabe destacar que la sola posibilidad de que un país pueda imponer una medida antidumping tiene como resultado disminuir las exportaciones hacia los países que aplican este tipo de medida, aun cuando el arancel vigente sea bajo. En efecto, la simple amenaza de un gravamen antidumping puede desalentar por sí sola la exportación de bienes hacia esos mercados. 
a) El algodón

El comercio mundial de algodón muestra severas distorsiones originadas en las políticas que se le aplican. El más grande productor mundial de algodón, los Estados Unidos, tiene costos de producción mucho más altos que países productores africanos, como Mali o Burkina Faso.

Los Estados Unidos es el país que brinda más apoyo a los productores de algodón. Sus 25.000 productores reciben 4.000 millones de dólares en subsidios del gobierno para producir algodón por un valor comercial de 3.000 millones de dólares. Tales subsidios empujan hacia abajo el precio del bien en el mercado mundial, perjudicando entre otros a los 11 millones de productores de África occidental. En 2001-2002 los precios al productor en los Estados Unidos fueron 91\% más altos que en el mercado mundial.

Por su parte, la Unión Europea entrega apoyo por cerca de 600 millones de dólares al año a sus propios productores de algodón, lo que indica que las proyecciones de los precios y las exportaciones de los países en desarrollo - especialmente de África-mejorarían grandemente si el apoyo de los países industrializados a sus productores se redujera o eliminara.

\section{b) El azúcar}

El azúcar es una de las materias primas más políticamente distorsionadas del mundo. La mayor parte del apoyo de la OCDE a los productores de azúcar se da en la Unión Europea, Japón y los Estados Unidos: 6.400 millones de dólares, que equivalen aproximadamente al valor de las exportaciones totales de los países en desarrollo.

Las altas barreras fronterizas, en combinación con los subsidios, mantienen los precios internos de este producto en los Estados Unidos y la Unión Europea en cifras que casi duplican los precios vigentes en los mercados mundiales.

Los elevados precios internos del azúcar en la Unión Europea, Japón y los Estados Unidos han alentado altos costos, una ineficiente producción local y el avance de los sustitutos del azúcar. Al mismo tiempo, han reducido el consumo total y han hecho que estos países, después de haber sido compradores netos de cerca de la mitad de las exportaciones mundiales de azúcar en el decenio de 1970, se hayan transformado gradualmente en vendedores netos a los mercados internacionales en la década de 1990.

Los subsidios de la Unión Europea permiten producir remolacha en la septentrional Finlandia, lo cual contribuye a que los productores azucareros eficientes pero pobres de los países tropicales apenas sobrevivan.
Los precios mundiales del azúcar están hoy por debajo de los costos de los productores más eficientes. El mercado mundial del azúcar se ha encogido a un comercio residual, con $80 \%$ de la producción mundial vendida a altos precios en mercados protegidos.

\section{c) El trigo}

Una situación similar se observa en los mercados trigueros de la Unión Europea, donde los altos precios internos han alentado la producción. Así, se ha pasado de importaciones netas cercanas a cinco millones de toneladas en el decenio de 1970 a exportaciones netas de 20 millones de toneladas a principios de la década de 1990.

Las exportaciones de trigo subsidiado de la Unión Europea continúan deprimiendo los precios mundiales. El trigo, que es uno de los productos más protegidos en la UE, recibió un apoyo a la producción que promedió casi 10.000 millones al año en 1999-2001 y que correspondió a una tasa de protección de casi $50 \%$.

\section{d) El maní}

El maní es uno de los principales productos oleaginosos. Se le cultiva ampliamente en los países en desarrollo e industrializados, y provee de subsistencia e ingresos a muchos campesinos pobres en el mundo en desarrollo, especialmente de África y Asia. Se estima que en Senegal, por ejemplo, un millón de personas (10\% de la población) se dedica a su producción y procesamiento.

La política estadounidense sobre el maní, altamente distorsionada por elevados subsidios y aranceles prohibitivos entre 1930 y 2001, fue reformada recientemente, pero mantiene todavía aranceles altos y redundantes.

Las mejoras netas de bienestar que traería la liberalización de los mercados del maní serían muy significativas para pequeñas economías agrarias como las de Malawi y otros países de África Occidental.

La liberalización de los mercados de productos con valor agregado - aceite y alimentos - se traduciría en avances en materia de bienestar en países africanos (Gambia, Malawi, Nigeria, Senegal, Sudáfrica).

\section{e) El arroz}

El arroz es el grano comestible más importante del mundo. Su producción y consumo están concentrados en China, India e Indonesia.

El apoyo otorgado al arroz en la OCDE asciende a más de 26.000 millones de dólares y en Japón a un asombroso $700 \%$ de sus costos de producción (a pre- 
cios mundiales). El escalonamiento arancelario es práctica corriente (desde el arroz paddy al molido) en muchos países, incluidos los de la Unión Europea, donde el arancel sobre el arroz molido es prohibitivo, excepto para pequeñas cuotas de importación preferenciales garantizadas a unos pocos países. Por ejemplo, el arancel que se aplica a las importaciones de arroz molido en la Unión Europea es de 80\%, comparado con el de $46 \%$ para el arroz marrón (brown rice).

Si se aplicasen reformas globales - la eliminación de todas las barreras fronterizas y de todos los apoyos- habría un aumento medio de los precios de cerca de $33 \%$, que se elevaría a $90 \%$ para el arroz de grano mediano y corto. Los productores de Camboya, China y Vietnam serían los principales beneficiados, junto con los consumidores de los países asiáticos de altos ingresos.

Como la mayor parte de la producción eficiente de arroz proviene de pequeños agricultores, las ganancias también favorecerían mucho a los pobres.

\section{Solución de controversias}

Los mecanismos de solución de controversias son una forma de corregir las inequidades anteriormente mencionadas. En el recuadro 2 se ilustra con un ejemplo la posibilidad de lograr respuestas a situaciones de competencia desleal en el comercio internacional.

\section{Recuadro 2 \\ LA EPOPEYA BRASILEÑA}

Si bien los mecanismos multilaterales de solución de controversias deben continuar perfeccionándose, pueden llegar a dar respuestas hoy a situaciones de competencia desleal en el comercio internacional. Éste es el caso de la lucha que dio Brasil contra los subsidios de Estados Unidos a sus productores de algodón.

El gobierno de Brasil presentó en marzo del 2003 ante la Organización Mundial del Comercio (OMC) una demanda contra los Estados Unidos, arguyendo que los subsidios que este país dio a sus productores de algodón — que totalizaron 13.100 millones de dólares entre 1999 y 2003 - causaron serios daños a Brasil debido a la caída del precio internacional de la fibra.

En abril de 2004, luego de más de un año de análisis, un panel de solución de controversias de la OMC determinó que los Estados Unidos excede regularmente el límite que ha declarado ante la OMC para los subsidios a sus productores de algodón. En particular, el panel encontró que:

- Estados Unidos usó subsidios a la exportación encubiertos para soslayar su compromiso ante la OMC de reducir los subsidios; y

- Los subsidios de apoyo internos de los Estados Unidos al algodón en el año comercial 2002/2003 tuvieron un significativo efecto depresivo sobre los precios, lo que ha acarreado un serio perjuicio a las exportaciones de Brasil. Esto quiere decir que los Estados Unidos tendrán que reformar sus prácticas actuales. En el veredicto final, dado a conocer en junio de 2004, el fallo preliminar del panel de abril fue ratificado.

Fuente: Elaboración basada en datos de Oxfam International (2004) y de organismos internacionales.

\section{X}

\section{La geografía de la pobreza rural}

Con la liberalización del comercio, la producción agrícola se desplazaría marginalmente del norte al sur, y los precios mundiales altamente deprimidos de muchas materias primas aumentarían: 10-20\% el del algodón, 20-40\% el de los productos lácteos, $10-20 \%$ el del maní, 33-90\% el del arroz y 20-40\% el del azúcar (Banco Mundial, 2003).
Cuatro países - Bangladesh, China, India e Indonesia - albergan el 75\% de la pobreza rural mundial. Es en Asia, por lo tanto, donde el crecimiento del ingreso rural tendría el mayor impacto sobre la pobreza.

Los mayores países industrializados que conforman el Grupo de los Siete son los únicos que pueden definir si el mundo avanzará hacia una globalización equitativa. 


\section{XI}

\section{El proteccionismo y el deterioro del medio ambiente}

El progreso económico es indispensable para abatir la pobreza, pero este progreso debe reconocer que los recursos naturales y la biodiversidad son activos que hay que preservar. No será posible reducir la pobreza si no se asegura la sustentabilidad de los ecosistemas cuando el crecimiento de la producción hace sentir cada vez más su presión sobre el medio ambiente y sobre recursos que son finitos.

Es un gran contrasentido que los países industrializados, que a menudo se hallan a la vanguardia de esta protección del medio ambiente, no sean consecuentes en lo que toca a la sustentabilidad de su propia economía rural, pues fuerzan a sus tierras ya cansadas y les exigen una producción agrícola cada vez mayor.

Al respecto es oportuno resaltar la siguiente cita (en traducción nuestra), tomada de un artículo de opinión aparecido en el Financial Times y que es extremadamente clara: Los subsidios a la agricultura promueven la sobreexplotación de las tierras agrícolas, llevan a la erosión de la superficie del suelo, a la contaminación por fertilizantes sintéticos y pesticidas y a la liberación de gases que aumentan el efecto invernadero. $^{7}$

\section{XII}

\section{Ganancias de la liberalización comercial}

El Banco Mundial consistentemente ha dado a conocer las distorsiones de los mercados mundiales causados por el proteccionismo y ha mostrado los beneficios que la liberalización del comercio significaría para las exportaciones, la producción y, en especial, para la reducción de la pobreza.

Hace poco más de dos años el Banco efectuó un ejercicio de simulación que intentaba estimar los beneficios que traería una Ronda de Doha que eliminara los aranceles a las importaciones, los subsidios a la exportación y los subsidios a la producción interna, en un calendario que se completaría hacia el año 2015 (Banco Mundial, 2001a). Según los resultados de esos cálculos (gráfico 2), las ganancias potenciales para el mundo de un acuerdo de tal tipo sería superior a los 800.000 millones de dólares anuales, de los cuales más de dos tercios estarían asociados a la liberalización agrícola; favorecerían tanto a los países en desarrollo como a los industrializados, y estos últimos recibirían aproximadamente el $40 \%$ de los beneficios.

El gráfico 3 muestra la reducción del número de pobres que originaría esta liberalización, reducción que se sumaría a la disminución proyectada por el creci-
GRAFICO 2

Ganancias potenciales de una Ronda de Doha que elimine las barreras arancelarias a los bienes hacia 2015

(En miles de millones de dólares anuales)

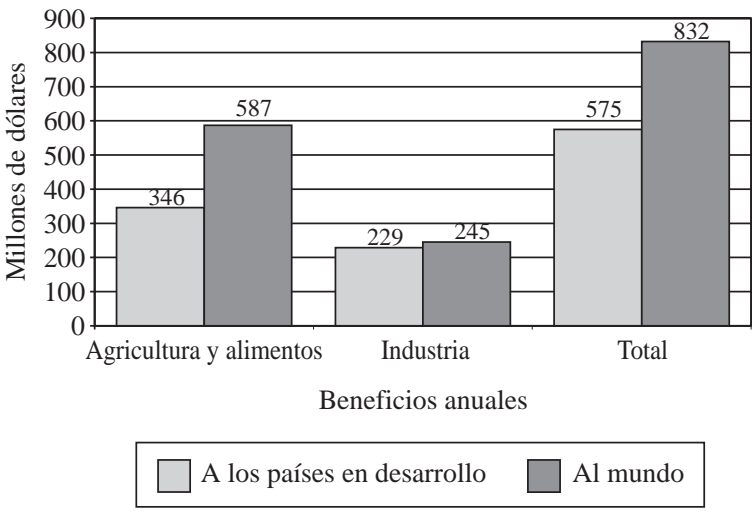

miento esperado de la economía sin esa eliminación de las barreras a las importaciones.

\footnotetext{
${ }^{7}$ Myers y Tickell (2003).
} 
GRAFICO 3

Países en desarrollo: La liberalización del comercio, una fuerza poderosa para reducir la pobreza mundial

(Reducción del número de pobres en millones de personas)

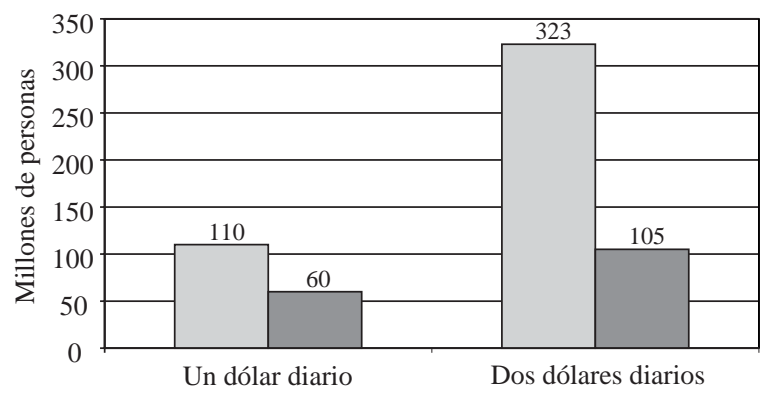

Todos los países en desarrollo

África

El número de personas que viven en pobreza extrema se reduciría en el mundo en desarrollo en 110 millones, es decir, en aproximadamente un $15 \%$ de los pobres con ingresos inferiores a un dólar diario que se estiman para 2015. El número de pobres con ingresos por debajo de dos dólares diarios caería en más de 300 millones.

En el informe Global Economic Prospects and the Developing Countries, 2004 (Banco Mundial, 2003) se presenta un ejercicio basado en una estimación menos optimista de lo que podría llegar a obtenerse de la negociación de la Ronda de Doha. En él se apunta a bajar los "techos arancelarios", determinando aranceles máximos de $10 \%$ para los productos agrícolas en los países industrializados y de $15 \%$ en los países en desarrollo; para las manufacturas los máximos serían de $5 \%$ y $10 \%$, respectivamente.

Este programa, combinado con el término de los subsidios a la agricultura y la eliminación de sus restricciones cuantitativas, podría significar nada menos que dos tercios de las ganancias generadas por la completa liberalización comercial. Si se implementara progresivamente en un período de cinco años y hubiera una respuesta positiva en materia de inversiones, en 2015 produciría para los países en desarrollo ingresos adicionales por cerca de 350.000 millones de dólares.
Por su parte, los países industrializados obtendrían ganancias del orden de los 170.000 millones.

Como se ve, los beneficios serían considerables y las ganancias para los países en desarrollo siete veces superiores a la ayuda concesional otorgada actualmente por los países industrializados.

El programa descrito reduciría la pobreza mundial en $8 \%$, es decir, en 61 millones de personas en el caso de la pobreza extrema, y en 144 millones de personas en el caso de los que hoy viven con menos de dos dólares al día.

Algunos analistas han planteado su preocupación por los desequilibrios entre naciones que podría traer consigo una liberalización del comercio mundial que elevara los precios internacionales de los bienes agrícolas, y han señalado en particular el efecto adverso que esto tendría en la seguridad alimentaria de los países que son importadores netos de alimentos.

Esta preocupación ha sido desvirtuada por diversos estudios. Por ejemplo, el Instituto Internacional de Investigaciones sobre Políticas Alimentarias (IIIPA, 2003) concluye que la eliminación del proteccionismo y los subsidios a la agricultura de los países industrializados triplicaría la balanza comercial positiva de los países en desarrollo, con un efecto favorable en todo tipo de países. En efecto, el cuadro 6 muestra que los países exportadores netos de bienes agrícolas aumentarían su saldo positivo y que los países importadores netos de bienes agrícolas reducirían su saldo negativo.

Lo que sí es efectivo es que la posibilidad de que los países incrementen las exportaciones agrícolas es de hecho sólo un "potencial", que debe ser complementado con medidas internas vinculadas con la oferta, como el mejoramiento de la infraestructura que utiliza el sector exportador (caminos, puertos, aduanas, etc.), y medidas relativas a la demanda, que consideren prácticas de comercialización modernas y la creciente sofisticación de los consumidores de los países industrializados, que pueden tender a "diferenciar" los productos según su origen. ${ }^{8}$

${ }^{8}$ Véase al respecto la experiencia de México, en Banco Mundial (2001b). 
CUADRO 6

Países en desarrollo: Impacto potencial en estos países de una liberalización comercial agrícola de los países industrializados

(En miles de millones de dólares)

\begin{tabular}{|c|c|c|c|}
\hline Región & $\begin{array}{l}\text { Nivel de la balanza comercial } \\
\text { (exportaciones menos } \\
\text { importaciones, o } \\
\text { exportaciones netas) } \\
\text { en } 1997\end{array}$ & $\begin{array}{c}\text { Nivel de la balanza comercial } \\
\text { agrícola tras la liberalización } \\
\text { comercial de los países } \\
\text { industrializados }\end{array}$ & $\begin{array}{c}\% \text { de aumento de las } \\
\text { exportaciones netas agrícolas } \\
\text { (el valor negativo corresponde } \\
\text { a disminución de las } \\
\text { importaciones netas agrícolas) }\end{array}$ \\
\hline África al sur del Sahara & 7,4 & 10,7 & 45 \\
\hline Asia & 12,3 & 22,8 & 85 \\
\hline América Latina y el Caribe & 31,7 & 46,4 & 47 \\
\hline Otros países en desarrollo & $-31,0$ & $-19,1$ & -38 \\
\hline Todos los países en desarrollo & 20,4 & 60,8 & 198 \\
\hline
\end{tabular}

Fuente: Datos del Instituto Internacional de Investigaciones sobre Políticas Alimentarias (IIIPA, 2003).

\section{XIII}

\section{Conclusiones}

Esperamos que este trabajo, en particular las cifras presentadas sobre los beneficios de la liberalización comercial, contribuya a dejar en claro la vinculación entre comercio internacional y pobreza mundial, que no era evidente de partida. Confiamos en que el reconocimiento cada vez más generalizado de los daños que provoca el proteccionismo dé paso a acciones concretas que superen el fracaso de la Conferencia Ministerial de Cancún en 2003 y destraben la Ronda de Doha, permitiendo entrar en la vía hacia una relación justa entre los países partícipes del comercio mundial.

Concluiremos con una cita (en traducción nuestra), extraída del New York Times, uno de los dia- rios de mayor impacto en la opinión pública mundial: Seguir el actual curso perverso aumentará la inestabilidad social y la devastación ambiental en el mundo en desarrollo. Significará un incremento de la inmigración ilegal para buscar empleo en países más ricos, en lugar de un aumento de los empleos e ingresos en el Tercer Mundo. Cualquier esfuerzo serio por combatir la pobreza extrema, promover el desarrollo en el Tercer Mundo y compartir los beneficios de la globalización debe empezar con un ataque radical contra los subsidios agrícolas y debe empezar ahora. ${ }^{9}$
Banco Mundial (2001a): Global Economic Prospects 2002, Washington, D.C.

(2001b): Mexico: Marketing of Fruits and Vegetables, Washington, D.C.

(2003): Global Economic Prospects, 2004, Washington, D.C. (2004a): World Development Indicators, 2004, Washington, D.C.

(2004b): Millennium Development Goals, Washington,

D.C., www.developmentgoals.org/Poverty.htm.

(2004c): Global Monitoring Report 2004, Washington, D.C

CEPAL (Comisión Económica para América Latina y el Caribe)

(2003): Panorama de la inserción internacional de América Latina y el Caribe, 2001-2002, LC/G.2189-P, Santiago de Chile, enero. Publicación de las Naciones Unidas, $\mathrm{N}^{\mathrm{o}}$ de venta: S.03.II.G.10.
Comité para el Desarrollo (2003): Comunicado del Comité para el Desarrollo, Washington, D.C., 13 de abril.

Environmental Working Group (2003): EWG Farm Subsidy Database, Washington, D.C., www.ewg.org.farm.

IIIPA (Instituto Internacional de Investigaciones sobre Políticas Alimentarias) (2003): How Much Does It Hurt? The Impact of Agricultural Trade Policies on Developing Countries, Washington, D.C.

Myers, N. y C. Tickell (2003): The No-win Madness of Catch-22 Subsidies, Financial Times, 28 de julio.

New York Times (2002): The Hypocrisy of Farm Subsidies, Nueva York, 2 de diciembre.

\footnotetext{
${ }^{9}$ New York Times (2002).
} 
OCDE (Organización para la Cooperación y Desarrollo Económicos) (2003): Agricultural Policies in OECD Countries. Monitoring and Evaluation 2003, París.

Oxfam International (2002): Rigged Rules and Double Standards: Trade, Globalization, and the Fight against Poverty, Washington, D.C., Market Trade Fair.

(2003): Running into the Sand. Why Failure at the Cancun Trade Talks Threatens the World's Poorest People, Oxfam Briefing Paper, $\mathrm{N}^{\circ}$ 53, Washington, D.C.
(2004): Dumping: the Beginning of the End? Implications of the Ruling in the Brazil/US Cotton Dispute, Oxfam Briefing Paper, $N^{\circ}$ 64, Washington, D.C.

Stern, N. (2002): Dynamic Development: Innovation and Inclusion, Munich Lectures in Economics, Munich, Center for Economic Studies.

The Economist (2003): The Cancun challenge, Londres, 4 de septiembre. World Bank Institute (2004): Rural Poverty \& Development, Washington, D.C., www.worldbank.org/wbi/sdruralpoverty/aboutus.html. 